\title{
Evaluación del Sistema Penal Oral Acusatorio: una visión desde el Consultorio Jurídico, Universidad Santo Tomás Bucaramanga, (Colombia)
}

\author{
Johana Sarit Riaño Acosta \\ Abogada, especialista en Derecho Administrativo y maestria en Derecho con énfasis en Derecho Administrativo por la \\ Universidad Santo Tomás Bucaramanga, Colombia, magister en Hermenéutica Jurídica y Derecho por la Universidad \\ Industrial de Santander - UIS, Licenciatura en Pensamiento Politico y Económico (en curso). Líder de la línea \\ "Violencia social y Derecho" del Grupo de Derecho Público. Correo electrónico: johanasarit@gmail.com
}

\section{Glendy Johanna Mejía García}

Abogada, maestría en Derecho (en curso) por la Universidad Santo Tomás Bucaramanga, Colombia. Correo electrónico: glendy.mejia.garcia@gmail.com

\section{Resumen}

El Sistema Penal Oral Acusatorio (SPOA) busca generar un modelo del proceso penal garantista cuyo eje principal gira en torno a la efectividad de las garantías procesales; la adecuada protección de los derechos fundamentales, (aquellos derechos que son adscritos universalmente a todos en cuanto personas, en cuanto a ciudadanos o en cuanto capaces de ejercicio. Ferrajoli, 2004, pp39-40), así como a la adaptación del sistema a las disposiciones contenidas en la Constitución Política de Colombia y en los tratados internacionales. En la actualidad no existe una investigación local que permita visualizar y analizar la efectividad de la implementación de este Sistema Penal Oral Acusatorio. Es por esto que esta investigación intenta, con base en la teoría del garantismo de Ferrajoli, establecer los niveles de efectividad, de eficiencia y protección de derechos fundamentales y garantías legales, que se observan en los procesos tramitados ante los jueces penales municipales, por estudiantes adscritos al Consultorio Jurídico de la Universidad Santo Tomás Seccional Bucaramanga en el período 2006-2010.

Palabras clave: Garantismo, Sistema Penal Oral Acusatorio, consultorio jurídico, defensa técnica, víctimas, política criminal.

\begin{abstract}
The Adversarial System Criminal Procedure ( in spanish SPOA) seeks to create a criminal process model with more guarantees, which focus is around the effectiveness of the process guarantees; adequate protection of fundamental rights (rights that are universally ascribed to all as people, as citizens or as capable persons. Ferrajoli, 2004, pp39-40) and also to adapt the system to the provisions of the Constitution of Colombia and international treaties. Currently there is no local investigation to visualize and analyze the effectiveness of the implementation of this Oral Criminal System. That is why this research tries, based on the Ferrajoli's theory of the guarantee, to establish the levels of effectiveness, efficiency and protection of fundamental rights and legal guarantees, which are observed in the process before the municipal criminal judges. All the investigaiton is made by students, who are working with the Legal Clinic of the University of Santo Tomas Bucaramanga, in the period between 2006 and 2010
\end{abstract}

KeyWords: Guarantees, The oral Accusatory Criminal System, legal clinic, Victims, criminal policy

\section{Résumé}

Le Oral sistema penal acusatório (SPOA) visa a criação de um modelo de garantias em processo penal cujo foco principal gira em torno da eficácia do processo; protecção adequada dos direitos fundamentais (direitos que são universalmente atribuídas a todos como pessoas, como cidadãos ou como capazes de exercício. Ferrajoli, 2004, pp39-40) e para adaptar o sistema ao disposições da Constituição da Colômbia e os tratados internacionais. Atualmente não há nenhuma investigação local para visualizar e analisar a eficácia da implementação deste sistema penal contraditório Oral. É por isso que esta pesquisa busca, com base na teoria da garantia de Ferrajoli, estabelecer os níveis de eficácia, eficiência e protecção dos direitos fundamentais e garantias legais, que são observados no processo perante os juízes criminais municipais, estudante atribuído à Clínica Jurídica da seção Universidade Santo Tomas Bucaramanga no período 2006-2010

Mots-clés: Garanties, Système Oral Contradictoire de Justice Pénale, CJ, Technologie de Défense, Les Victimes, La Politique Pénale. 



\title{
Evaluación del Sistema Penal Oral Acusatorio: una visión desde el Consultorio Jurídico, Universidad Santo Tomás Bucaramanga, (Colombia) ${ }^{*}$
}

\author{
Johana Sarit Riaño Acosta \\ Glendy Johanna Mejía García
}

\section{METODOLOGÍA}

El estudio a partir del cual se desarrolló el presente artículo tiene un alcance descriptivo, con un enfoque mixto de acuerdo con las fases del proceso. La primera se desarrolló bajo el enfoque cuantitativo y la segunda por el cualitativo. La primera consistió en la elaboración de indicadores de los procesos, partiendo de la información estadística suministrada por la Fiscalía General de la Nación, la Defensoría del Pueblo y juzgados penales municipales de Bucaramanga y de los expedientes que constituyen el desarrollo procesal dentro de la investigación y juzgamiento en la comisión de un delito.

Una segunda fase correspondió al análisis cualitativo acerca de la forma en que los jueces penales municipales de Bucaramanga argumentan sus fallos, este análisis se realizó a partir de los métodos y técnicas de interpretación judicial propios de la disciplina jurídica. Por último, se realizó la evaluación del Sistema Penal Oral Acusatorio (SPOA), desde los hallazgos obtenidos en las dos fases anteriores.

El carácter de la investigación desarrollada es de tipo sociojurídico toda vez que a partir de una situación fáctica, como lo constituyen los procesos de conocimiento de los jueces penales municipales de Bucaramanga en el período 2006-2010, se construyeron supuestos epistemológicos y metodológicos para evaluar la aplicación del Sistema Penal Oral Acusatorio, desde los siguientes parámetros de evaluación:

1. Descongestión de los despachos judiciales.

2. Eficiencia y garantismo del sistema penal, a la luz de los principios de contradicción, oralidad, publicidad del juicio, la paridad entre acusaciones y defensa, la separación rígida de juez y acusación, la presunción de inocencia, la carga de la prueba para el que acusa y principio del juez natural.

3. Confianza de la ciudadanía en el Sistema Penal.

4. Calidad de las decisiones judiciales.

5. La anterior descripción permitió el desarrollo del proyecto y de la producción académica aquí presentada.

* Este artículo es producto del proyecto de investigación: Evaluación SPOA (Ley 906 de 2004), en juzgados penales municipales de Bucaramanga 2006-2010. Convocatoria interna. Grupo de Derecho Público USTABGA; Línea Violencia Social y Derecho; Facultad de Derecho de la Universidad Santo Tomás Bucaramanga, Colombia. 


\section{DEFENSA TÉCNICA Y REPRESENTACIÓN DE LAS VÍCTIMAS POR PARTE DE ESTUDIANTES DEL CONSULTORIO JURÍDICO DE LA UNIVERSIDAD SANTO TOMÁS SECCIONAL BUCARAMANGA}

Desde el año 2006 y hasta el 2010, los estudiantes del Consultorio Jurídico (C.J.) han actuado en un total de 490 procesos, de los cuales 278 son de conocimiento de los juzgados penales municipales; en estos procesos, los estudiantes actuaron en calidad de defensores públicos en un $61 \%$ y como representantes de víctimas en un $39 \%{ }^{1}$. Al contrastar la defensoría pública con la representación de víctimas desde el C.J., se observó que los delitos que en mayor medida solicitan la defensoría pública, son aquellos que protegen la familia con un $32 \%$, seguido por los delitos contra el patrimonio económico con un $21 \%$ y los delitos contra la vida e integridad personal con un $13 \%$. Por otro lado, para actuar en calidad de representantes de víctimas, el panorama es similar; en los delitos contra la familia se realizó acompañamiento en un $23 \%$, en los delitos contra la vida e integridad personal en un $7 \%$, y en delitos contra el patrimonio económico en un $4 \%$ de los casos.

Figura 1. Calidad en la que actúan los estudiantes del Consultorio Jurídico de acuerdo con los tipos penales

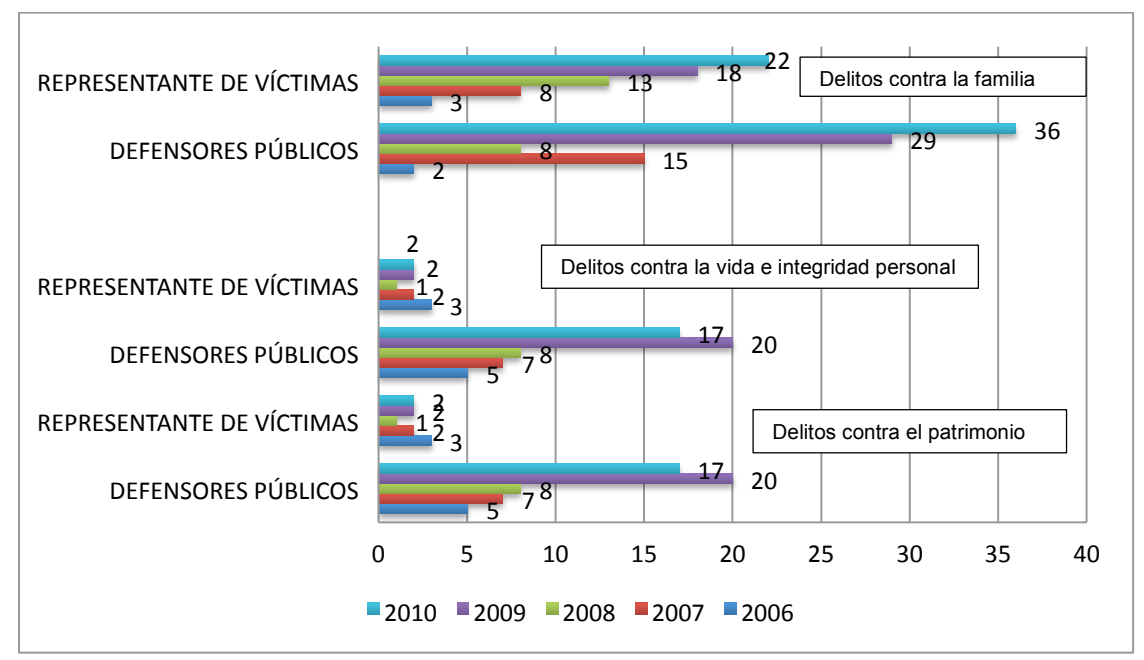

Fuente: Elaboración propia.

1 El artículo 137 de la Ley 906 de 2004 en su numeral 3, permite que la representación de las víctimas pueda ser ejercida por parte de estudiantes de C.J. 
Desde el 2006 hasta el 2009 se observó un incremento del 58\% en las solicitudes de acompañamiento ${ }^{2}$ en los delitos contra el patrimonio económico, en los delitos contra la familia en un $91 \%$ y en los delitos contra la vida e integridad personal en un 64\%; sin embargo, para los años 2009 al 2010, la disminución en las solicitudes de acompañamiento en los delitos contra el patrimonio económico desciende a un $16 \%$ y en delitos contra la vida e integridad personal, a un $21 \%$.

En lo que respecta a la calidad adoptada para actuar como defensores públicos en los delitos contra el patrimonio económico, los estudiantes de C.J. asumieron en un $84 \%$ y en un $16 \%$ en calidad de representante de víctimas; para los delitos contra la vida e integridad personal, la defensa técnica se asumió en un $65 \%$ y la representación de la víctima en un 35\%; finalmente, en los delitos contra la familia, la defensa se asumió en un 58\% y la representación en un $42 \%$.

Es innegable el papel que vienen desarrollando los estudiantes del C.J., especialmente en lo que toca a la defensoría pública, pues permite facilitar el acceso a la administración de justicia a las personas que por sus condiciones económicas no pueden costear los servicios de un abogado. Sin embargo, y pese al gran número de procesos en los que participa el estudiante, se observa que en un $73 \%$ el procesado no comparece a las audiencias ${ }^{3}$, lo que implica una desventaja para el defensor en el momento de afrontar la teoría del caso, en contraste con la capacidad investigativa de la Fiscalía General de la Nación.

Ante la no comparecencia del investigado, el Estatuto Procesal Penal, establece que el juez penal municipal con función de control de garantías debe verificar que se hayan agotado de forma suficiente y razonable los mecanismos de búsqueda por parte de la Fiscalía General de la Nación y que el envío de las citaciones se haya realizado a las direcciones que obran en el expediente, así como confrontar el motivo de devolución de las citaciones (Ley 1369 de 2009) ${ }^{4}$.

\section{CRISIS EN LA NORMATIVA DEL SISTEMA PENAL ORAL ACUSATORIO}

Como ya se ha mencionado, los delitos en los que en mayor medida los estudiantes del C.J. actúan en calidad de defensores públicos tienen que ver con conductas que

2 Estudio de los citatorios enviados por el Centro de Servicios Judiciales de la Rama Judicial al Consultorio Jurídico, solicitando acompañamiento como defensores públicos o representantes de víctimas para los procesos de conocimiento de los juzgados penales municipales.

3 La causa más común de esta situación es el cambio constante de residencia del procesado y en menor medida el desinterés del procesado en el trámite procesal.

4 Por medio de la cual se ordena el régimen de los servicios postales y se dictan otras disposiciones; se establecen los criterios que tiene la mensajería para ser certificada. 
atentan contra el patrimonio económico ${ }^{5}$, contra la familia ${ }^{6}$ y la vida e integridad personal7; estos delitos han sido objeto de múltiples modificaciones legislativas, con el propósito de transmitir un mensaje de represión a la sociedad, a través del castigo representado en el aumento de la pena, para de este modo lograr la disminución en la comisión de dichas conductas.

La pena tiene una serie de funciones, entre las cuales se encuentran la prevención general; esta tiene dos aspectos: de carácter "negativo", el cual se define como una advertencia dirigida a las personas que intentan transgredir el orden jurídico; el "positivo", o estabilizador de las relaciones y estructuras fundamentales de la sociedad, con el fin de proteger y asegurar a los miembros de la sociedad . $^{8}$

Conforme a los principios esenciales del Estado social de derecho, la imposición de la pena debe responder a un principio de necesidad, la cual tiene tres finalidades, según lo enunciado por la Corte Constitucional ${ }^{9}$ (2002), a) La preservación del orden jurídico. b) Advertir a las personas para disminuir la comisión de delitos. c) Si se comete la infracción el Estado debe propender por conservar y proteger los derechos objeto de tutela jurídica y la reincorporación del autor de la conducta punible a la sociedad.

De acuerdo con el principio de necesidad, y unido a los factores sociales propios de la población colombiana, el legislador se ve en la obligación de generar leyes que permitan restablecer el orden jurídico y garantizar a los miembros de la sociedad la confianza en las instituciones.

Desde la vigencia del Código Penal, los delitos mencionados anteriormente han sufrido el siguiente número de modificaciones: tres en los delitos contra la familia ${ }^{10}$ $\mathrm{y}$ tres en los delitos contra el patrimonio económico ${ }^{11}$, y una en los delitos contra la vida e integridad personal ${ }^{12}$. Este tipo de modificaciones debería incidir en el índice

5 Del $84 \%$ de las defensorías públicas realizadas por los estudiantes del C.J. en los delitos contra el patrimonio económico, se discriminan por tipos penales de la siguiente manera: $6 \%$ en hurto simple e igualmente en hurto calificado, en un $39 \%$ en hurto agravado, en un $15 \%$ en hurto calificado y agravado, en un $2 \%$ usurpación de tierra, en un $12 \%$ abuso de confianza, en $1 \%$ extorsión y acceso abusivo a un sistema informático y hurto por medio informático y semejantes en concurso, en un $7 \%$ en estafa y en un $10 \%$ en daño en bien ajeno.

6 Del $58 \%$ de las defensorías públicas realizadas por los estudiantes del C.J. en los delitos contra la familia se discrimina por tipos penales de la siguiente manera: en un $97 \%$ se apoyó en inasistencia alimentaria y en un $3 \%$ violencia intrafamiliar.

7 Del $65 \%$ de las defensorías públicas realizadas por los estudiantes del C.J. en los delitos contra la vida e integridad personal, se discrimina por tipos penales de la siguiente manera: en un $46 \%$ lesiones personales, en un $25 \%$ lesiones personales dolosas y en un $29 \%$ lesiones personales culposas.

8 Corte Constitucional. Sentencia C-806 de 2002.

9 Corte Constitucional. Sentencia C-806 de 2002, p. 10.

10 En el tipo de violencia intrafamiliar, las modificaciones se encuentra en la Ley 882 de 2004 y Ley 1142 de 2007, en el tipo de inasistencia alimentaria en la Ley 1181 de 2007.

11 En el tipo de hurto en la Ley 813 de 2003, la Ley 1142 de 2007, en el tipo de estafa y abuso de confianza la Ley 1474 de 2011.

12 En el tipo penal de lesiones en la Ley 1639 de 2013. 
de comisión de delitos; sin embargo, de conformidad con las solicitudes del Centro de Servicios Judiciales efectuadas al C.J., solicitando estudiantes como defensores públicos, se observa un incremento de conformidad con los siguientes resultados ${ }^{13}$ : en el caso de los delitos contra el patrimonio económico su comisión aumentó en un $58 \%$, en los delitos contra la familia en un $91 \%$ y en los delitos contra la vida e integridad personal un 64\%.

Cabe destacar que para el año 2009, el Centro de Servicios Judiciales solicitó en mayor medida estudiantes del C.J. para que asumieran el rol de defensores públicos, en los delitos contra el patrimonio económico y contra la vida e integridad personal. Para los delitos contra la familia, el aumento se presenta en el año 2010, lo que lleva a concluir que en el año 2009 se presentó un aumentó en la criminalidad en el país; lo anterior, se corrobora igualmente con el resultado de la Investigación Criminológica realizada por la analista Gloria Espino-Duque para el Observatorio del Delito de la Policía Nacional $(2010)^{14}$.

De acuerdo con los datos demostrados anteriormente, el aumento en los hurtos $^{15}$ a través de diversas modalidades que no se encontraban contempladas en el Código Penal, llevó al legislador a sancionar severamente a quienes realizaban estas conductas. En los delitos contra la familia -inasistencia alimentaria y violencia intrafamiliar-el legislador realizó modificaciones cuando la víctima se trataba de un niño, niña o adolescente y de mujeres. El principio de legalidad, tal y como lo concibe Ferrajoli (2004, pp. 12-13), es la herramienta mediante la cual el Estado ha logrado el control de las transgresiones a los derechos de las personas, es así que, a través de las leyes se instituyen vínculos sustanciales en tutela de derechos, se limitan los poderes de los sujetos más fuertes en garantía de las libertades o de las expectativas de los sujetos más débiles.

En el campo penal es propia la función represiva de la ley por cuanto busca imponer sus mandatos y prevenir violaciones; dentro de un sistema garantista se tiende a proteger a la persona del arbitrio y el error. De esta concepción se desprenden las garantías penales que hacen referencia a las técnicas en el plano legal, las cuales aseguran al máximo la comprobación de la verdad jurídica, es decir, garantizan la verificabilidad y refutabilidad de los delitos definidos por la ley, vinculando al legislador a satisfacer las condiciones para que se permita la intervención del Estado.

13 Datos tomados de las citaciones enviadas al C.J. por el Centro de Servicios Judiciales de la Rama Judicial, para acompañamiento del estudiante en calidad de defensor público o representante de víctima.

14 Según la Investigación Criminológica, realizada por el Observatorio del Delito de la Policía Nacional, denota que para el año 2009 el índice de criminalidad se encontraba en un 0,072, índice superior al promedio comparado con los años anteriores.

15 Según la Investigación Criminológica realizada por el Observatorio del Delito de la Policía Nacional denota que para el año 2009 el índice de criminalidad se encontraba en un 0,072, índice superior al promedio comparado con los años anteriores. 
Este tópico dentro de la investigación estuvo referenciado en las modificaciones legislativas que se realizaron durante el período objeto de investigación, en los delitos contra el patrimonio económico, contra la familia y contra la vida e integridad personal; modificaciones que se plantearon con el fin de disminuir la criminalidad especialmente en estos delitos en el país.

Las reformas surgen teniendo en cuenta el incremento y la aparición de diversos fenómenos sociales que repercuten de forma negativa en los derechos fundamentales de una persona, con lo que se impone la necesidad de generar leyes que permitan garantizar el orden jurídico y restablecer en los miembros de la sociedad, la confianza en las instituciones jurídicas.

Si bien es cierto, en el período comprendido entre el año 2004, fecha de creación del Sistema Penal Oral Acusatorio, y el 2010, fecha hasta la cual se realiza el análisis de la investigación, se han presentado reformas en delitos contra la familia ${ }^{16}$ y contra el patrimonio económico ${ }^{17}$, con el fin de prevenir y reprimir la actividad delictiva, a través del aumento de penas, se observa que la intervención legislativa no ha producido los resultados esperados, por cuanto el número de delitos conocidos desde el primer año de la investigación ha ido en aumento detectándose, por consiguiente, una mayor tasa de criminalidad.

Las modificaciones o reformas legislativas hacen parte del núcleo de la función de la pena en lo que respecta en la prevención general en la comisión de delitos; sin embargo, teniendo en cuenta las muestras obtenidas, se puede inferir que el sistema garantista penal no ha dado resultados esperados, por cuanto la función legislativa no cumple con las expectativas sociales y la protección de los derechos fundamentales de los asociados; se trata entonces de aplicar paliativos que no disminuyen el índice de criminalidad, ya sea, desde el incremento en las penas, o a partir del aumento en la especialidad de las conductas punibles; medidas que en nada aportan a la descongestión judicial, ni a la verdadera garantía de los derechos fundamentales; luego no podría afirmarse que exista una verdadera efectivización del derecho como lo propone Ferrajoli (2004).

\section{LA EFICACIA DEL SISTEMA A TRAVÉS DEL DESARROLLO DE LAS ETAPAS PROCESALES}

El Sistema Penal Oral Acusatorio encuentra su sustento en los principios establecidos en la Constitución colombiana y en los tratados internacionales ${ }^{18}$, los cuales establecen que en todo proceso penal debe prevalecer la publicidad, la

16 En el tipo de violencia intrafamiliar, las modificaciones se encuentran en la Ley 882 de 2004, Ley 890 de 2004 y Ley 1142 de 2007. En el tipo de inasistencia alimentaria la Ley 1181 de 2007.

17 En el tipo de hurto en la Ley 813 de 2003.

18 Declaración Universal de Derechos Humanos, Pacto Internacional de Derechos Civiles y Políticos, la Convención Americana de Derechos Humanos. 
oralidad, la celeridad, la inmediación y la contradicción. A partir de estos principios, se analizaron los tipos penales de los procesos adelantados en el C.J., en cada una de las etapas procesales, con el fin de determinar el grado de cumplimiento de eficiencia $^{19}$ del SPOA.

Con la formulación de imputación se formaliza la investigación penal. A partir de esta etapa se materializa el derecho de defensa del procesado. Este acto es de vital importancia, por cuanto es a partir de él que el procesado conoce los hechos por los cuales se le investiga.

Empero, durante la etapa de indagación, en ciertas circunstancias la Fiscalía General de la Nación no suministra información a la defensa (para el caso de los estudiantes de C.J.), aún a pesar de que en reiterados pronunciamientos, la Corte Constitucional (Sentencias C-127 de 2011, M.P. María Victoria Calle Correa; C-799 de 2005 M.P. Jaime Araujo Rentería; C-1260 de 2005, M.P. Clara Inés Vargas Hernández; C-1194 de 2005, M.P. Marco Gerardo Monroy Cabra) haya expresado que el derecho de defensa en el Sistema Penal Oral Acusatorio se ejerce incluso antes de que la investigación penal sea puesta en conocimiento por parte de un juez de control de garantías.

En el caso del C.J., del total de los procesos adelantados por delitos contra el patrimonio económico, se tiene evidencia que la imputación se realizó en un $27 \%$, del total de los delitos contra la familia en un 58\% y en los delitos contra la vida e integridad personal se realizó en un 15\%.

En gran medida, las solicitudes de imputación se efectúan en los delitos contra la familia, delitos contra el patrimonio económico y contra la vida e integridad personal. De la revisión de cada uno de los procesos estudiados del C.J., se observa un estricto control por parte de los jueces de Control de Garantías, quienes se encuentran investidos con una función meramente constitucional, mediante la cual buscan la protección de los derechos fundamentales, especialmente la que tiene que ver con la citación al procesado, toda vez que se procede a la suspensión de la audiencia, hasta que la Fiscalía despliegue toda la actividad tendiente a lograr la comparecencia del procesado. En el caso de contumacia, se verifica que las citaciones se hayan enviado y en audiencia se comprueba si esta fue recibida o no (Ley 1369 de 2009).

19 El término eficiencia, se define por la Real Academia Española como: "la capacidad de disponer de alguien o algo para conseguir un efecto determinado" Recuperado de http://www.rae.es/. Fecha 5 de agosto de 2014 . 
Figura 2. Comparencia del investigado al proceso penal

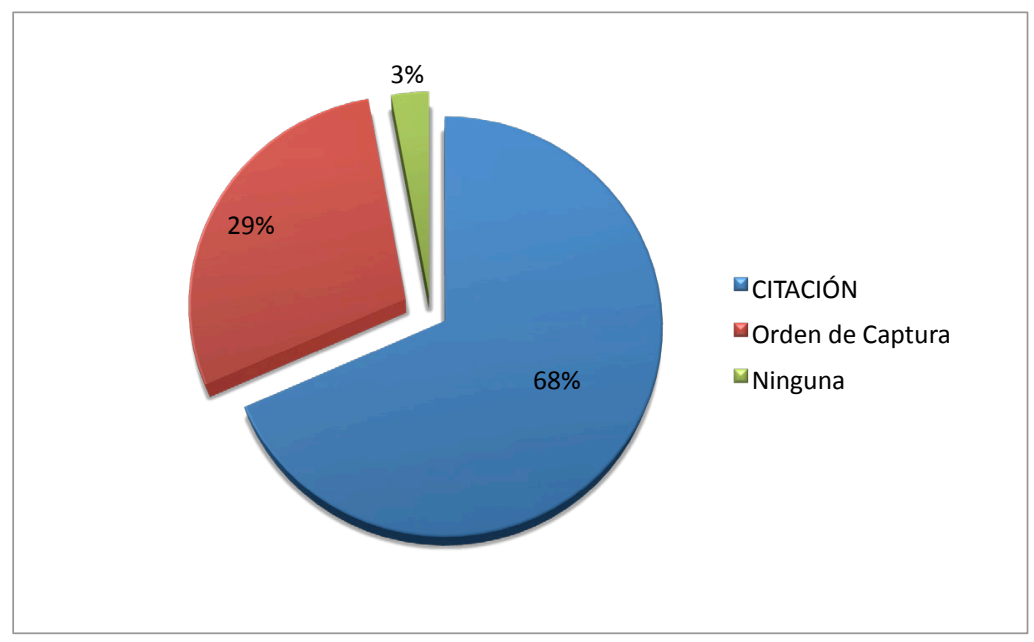

Fuente: Elaboración propia.

La audiencia de formulación de acusación es el momento en el cual el delegado de la Fiscalía le informa al procesado y a su defensa los elementos materiales probatorios con que cuenta para demostrar que la comisión del delito puede endilgarse o no al investigado en calidad de autor, coautor partícipe o cómplice ${ }^{20}$. De todos los delitos contra el patrimonio económico adelantados en el C.J., esta audiencia evidenció que se realizó en un $25 \%$, en los delitos contra la familia se evidenció su realización en un $59 \%$, y en los delitos contra la vida e integridad personal en un $16 \%$.

La audiencia de juicio oral es el momento en el cual se practican todas las pruebas (documentales o testimoniales) solicitadas en las etapas anteriores por las partes. En esta etapa se debaten de manera oral y pública las teorías de responsabilidad de la Fiscalía y la teoría de inocencia de la defensa. En la presente investigación se evidenció que la audiencia de juicio oral en los delitos contra el patrimonio económico se realizó en un $26 \%$, contra la familia en un $56 \%$ y contra la vida e integridad personal en un $18 \%$.

Un aspecto por resaltar y de vital importancia tiene que ver con las labores de investigación realizadas por la Policía Judicial, tendientes a demostrar el arraigo económico, personal, social y familiar del procesado. Este arraigo permite al defensor público conocer el ámbito social y personal en el que se desenvuelve el procesado, factores que van a influir en el fortalecimiento de la teoría del caso de la defensa.

20 En un $89 \%$ los delitos fueron cometidos por el género masculino, en un $7 \%$ fueron cometidos por el género femenino, en un 3\% fueron cometidos por 2 o más hombres y en $1 \%$ por 2 o más mujeres. Los delitos en los que mayor participación tienen los hombres son los delitos contra la familia y las mujeres, en los delitos contra el patrimonio económico y en igual proporción contra la vida e integridad personal. 
Al contrastar dentro de la investigación, la fecha de realización del estudio por parte de la Policia Judicial y la fecha en la cual el informe de arraigo se introduce y es debatido en el juicio oral, el tiempo que ha transcurrido es de aproximadamente dos años; lo que implica una ineficacia del sistema penal para garantizar de manera total los derechos de la víctima, así como para brindar un mayor alcance al derecho de defensa.

Así mismo y ante lo anterior, los C.J. no cuentan con un grupo de investigadores especializados con el fin de llevar a cabo labores de campo. Para el caso del C.J. de la Universidad Santo Tomás Seccional Bucaramanga, algunas de estas actividades son apoyadas por los estudiantes de la Tecnología en Investigación Criminal y Ciencias Forenses de la Universidad Autónoma de Bucaramanga (UNAB), en virtud del convenio de cooperación interistitucional suscrito entre las dos universidades. Sin embargo, dada la responsabilidad y las limitaciones de carácter académico que implican este tipo de ejercicios, no se puede afirmar que exista una estructura sólida, que permita abordar de manera integral investigaciones de campo, lo que implica posiblemente una falla en el sistema, pues el Estado estaría delegando una responsabilidad que solo le atañe a él y que tiene que ver con la protección al derecho de defensa integral de quienes no pueden acceder a los servicios de un abogado.

Figura 3. Desarrollo legal de los procesos del C.J.

Universidad Santo Tomás Seccional Bucaramanga

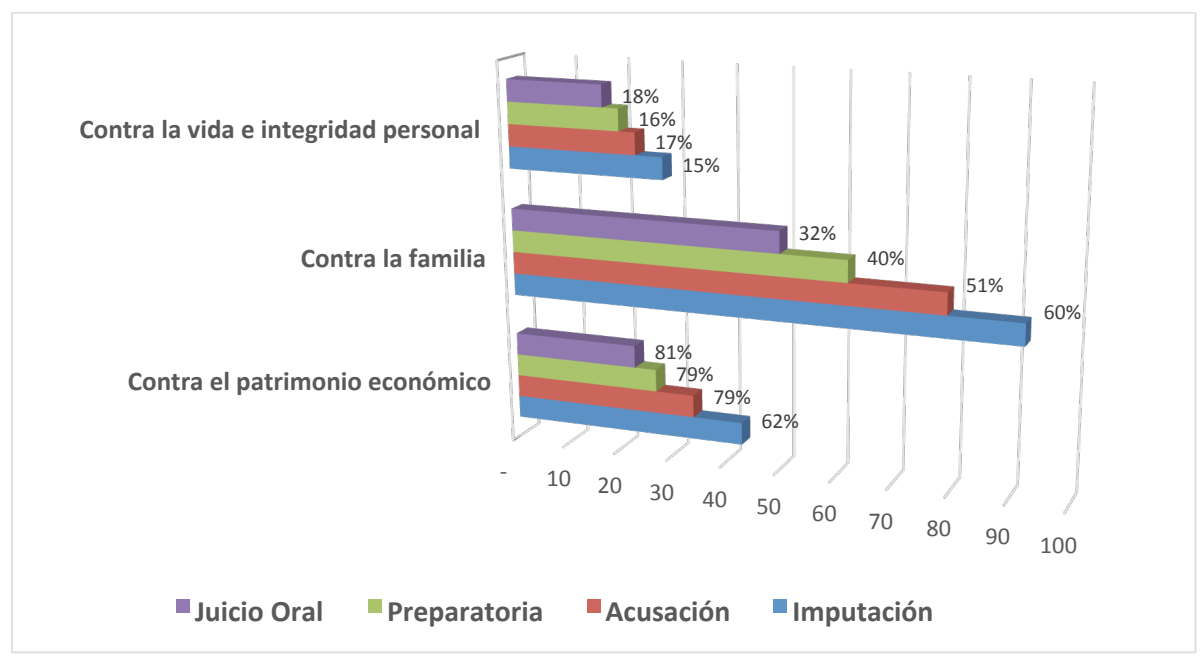

Fuente: Elaboración propia. 
Como se puede observar en la gráfica precedente, respecto a los delitos contra la familia, un 59\% llega únicamente a imputación y solo el $32 \%$ llega a audiencia de juicio oral. No sucede lo mismo con los delitos contra el patrimonio económico y contra la vida e integridad personal, en atención a que el porcentaje de procesos en juicio oral es superior al de la audiencia de imputación; ello en atención, a que gran cantidad de solicitudes enviadas por el Centro de Servicios Judiciales al C.J. son especialmente para realizar acompañamiento al procesado o la víctima en esta audiencia; lo anterior muestra una nueva falencia en el sistema, pues los estudiantes, en este estado del proceso, no pueden adelantar una adecuada defensa técnica.

\section{EL PAPEL GARANTISTA DEL JUEZ}

Por otro lado, la labor jurisdiccional ha desempeñado un papel importante en lo que respecta a la protección de las garantías primarias, por cuanto, con su actuar busca restablecer la confianza en la administración de justicia y a través de sus decisiones judiciales dar cuenta que en ejercicio de la aplicación de la ley penal, no solo se logra materializar los fines de la prevención general, sino también se muestra a la sociedad el cumplimento de tales fines.

Teniendo en cuenta las decisiones judiciales que se analizaron dentro de la investigación, se observa un alto margen de protección de las garantías, especialmente en lo que toca al debido proceso y a la libertad, que son objeto de restricción dentro de un proceso penal, por cuanto el juez opta por un papel proteccionista respecto de los derechos fundamentales tanto del procesado como de la víctima.

De los 278 procesos analizados, un $40 \%$ de los procesos analizados llegaron a fallo condenatorio. Al analizar los fallos, los jueces exponen en sus argumentos un fin sociojurídico para fundamentar sus decisiones, en atención a que se busca en principio influir en la sociedad y en la disminución de la comisión de las conductas punibles. Se observa, igualmente, que el juez propende respecto al procesado a fin de garantizarle un debido proceso y a las garantías de verdad y justicia, así mismo, brinda los medios para ser reincorporado a la sociedad.

\section{GARANTISMO EN EL DESARROLLO DEL PROCESO PENAL}

De los 278 procesos que se tomaron como muestra para la investigación, se observó que un gran número de procesos no llegaron a la etapa de juicio, toda vez que se acogieron a formas anormales de terminación del proceso. En este sentido, un $9 \%$ de los procesos culminaron con aplicación de la figura de allanamiento y preacuerdo, la figura de la preclusión representa un total del $18 \%$ y en un $1 \%$ de los procesos se aplicó el principio de oportunidad. En el estado de la investigación, el $32 \%$ de los procesos estudiados se encuentra a la espera de la etapa del juicio oral y la correspondiente sentencia.

Revisando la línea de tiempo en que se produce la investigación y los procesos que han culminado con sentencia o han finalizado de manera anormal, se puede 
evidenciar la falta de cumplimiento del principio de celeridad, pues las actuaciones procesales no se realizan en el término legal establecido, sino por el contrario, en su mayoría, son objeto de aplazamientos y suspensiones, que tienen que ver con factores de falta de elementos físicos para realizar audiencias, cruce de horario de audiencias o con otros compromisos por parte de las partes, que, de la misma manera, generan una desmaterialización de la idea de pronta justicia, tanto para la víctima como para el procesado, y una vulneración de las garantías procesales a las que tienen derecho.

A pesar de la poca celeridad en los procesos, cuando la persona reconoce el daño ocasionado y desea asumir la responsabilidad penal, se observa un alto impacto en el empleo de los métodos anormales de terminación del proceso, los cuales hacen referencia a la figura del allanamiento, preacuerdos y preclusiones; respecto a esta última, muchas de ellas preferidas por cumplimiento en los acuerdos conciliatorios. Estas figuras han evitado la congestión del aparato judicial y han permitido que en cierta medida se agilice la aplicación de justicia. No obstante, cuando se accede por parte de procesado a un método anormal de terminación del proceso, este es quien se beneficia en mayor medida; sin embargo, no sucede lo mismo con la víctima, pues en la mayoría de las oportunidades esta no logra obtener su reparación, por lo que tiene que acudir a otra clase de procesos ante la jurisdicción civil, lo que impone una carga adicional para lograr la reparación integral; lo anterior, se traduce en una revictimización que podría llegar a repercutir en el grado de confianza frente al SPOA.

\section{EVALUACIÓN DEL SISTEMA PENAL ORAL ACUSATORIO}

La evaluación del SPOA propuesta desde la presente investigación, a partir de los procesos penales tramitados por estudiantes del C.J. Universidad Santo Tomas Seccional Bucaramanga, permitió identificar y contrastar los siguientes aspectos, a fin de determinar su grado de eficiencia.
a. Impunidad
b. Política criminal
c. Mecanismos de justicias penales a partir de C.J.
d. Criminalidad oculta

La eficiencia es definida por el Diccionario de la Real Academia (2002) como "la capacidad de disponer de alguien o de algo para conseguir un efecto determinado"21, igualmente, esta palabra deriva del latín efficientǐa, que significa acción, fuerza o producción. Aplicando este concepto a la presente investigación, se buscó estudiar si todos los actores ${ }^{22}$ que se encuentran involucrados dentro del SPOA, permiten

21 Recuperado de http://www.rae.es/. Fecha 5 de agosto de 2014.

22 En esta investigación, por actores del SPOA se deben entender Fiscalía General de la Nación, fiscales delegados antes los jueces penales municipales, defensa técnica y representación de víctimas, realizada por los estudiantes del C.J. de la Universidad Santo Tomás. Jueces penales con función de garantías y jueces penales municipales con función de conocimiento. 
la realizabilidad de las etapas procesales contempladas en la legislación penal, así como la protección de los derechos humanos y, de este modo, lograr una verdadera administración de justicia.

La eficiencia en el Sistema Penal Oral Acusatorio impone la observación desde dos puntos de vista coyunturalmente opuestos; el primero de ellos tiene que ver necesariamente con la existencia o no de impunidad como factor determinante en la eficiencia de un sistema de justicia penal y desde la segunda perspectiva, impone la observación de la operatividad judicial, en el entendido del desarrollo de los fines deontológicos de celeridad, eficiencia y facilidad de acceso a la justicia.

\section{La impunidad en el Sistema Penal Oral Acusatorio}

La impunidad es un concepto ligado a la ineficacia del derecho penal para controlar la criminalidad (Barreto y Rivera, 2009), es decir, si ninguno de los partícipes desarrolla sus funciones constitucionales o legales en la medida exacta, no se alcanza la finalidad propuesta por el sistema penal, la justicia, que en el campo penal abarca un espectro más amplio al concepto de imposición de un castigo, concretándose en otorgar justicia de manera objetiva y equitativa a quien ha sufrido un daño a causa de un delito. Sin embargo, la realidad social muestra otra visión del sistema penal; soporte de esta afirmación, lo constituyen las diversas noticias tanto de medios radiales como de periódicos, tales como La W (2012), El Espectador (2011) y El Tiempo (2013) ${ }^{23}$, que enuncian las dificultades por las cuales atraviesa el Sistema, dificultades que lo hacen insostenible y que determina la inconformidad de la sociedad frente al alto índice de impunidad.

Kai Ambos (1999) señala cinco impunidades procesales: a) Impunidad fáctica, generada por la ausencia de denuncia. b) Impunidad investigativa, se presenta cuando no existe una investigación de los hechos o no es realizada de manera eficiente. c) Impunidad por congestión, debido a la sobrecarga en la justicia. d) Impunidad legal, cuando el legislador crea normas especiales para ciertos casos. Y e) Impunidad delictuosa, cuando no se respeta la función de cada uno de los actores.

De acuerdo con Kai Ambos (1999) y el análisis que se realizó sobre la muestra de procesos tramitados en el C.J. se concluyó que no se evidenció impunidad investigativa, por cuanto la administración de justicia sobre estos procesos no fue plenamente eficiente; ello si se parte de la base de que si bien se realizaron todas las etapas procesales, estas no se hicieron en un tiempo razonable.

23 "A pesar de la crisis el Sistema Penal Oral Acusatorio no tiene "reversa", dice el Ministro de Justicia", (noticia W radio del 30 de abril de 2012); "El colapso de la justicia penal", (noticia El Espectador del 31 de enero de 2011); "El estudio estará en manos del Ministerio de Justicia, la Corte Suprema y de la Fiscalía”, (noticia El Tiempo, 2013). 
En lo referente a la impunidad legal en los términos del mismo autor, se evidenció que los tipos penales analizados fueron objeto de varias modificaciones legislativas tendientes a la disminución de los índices de criminalidad; disminución que en la práctica no se refleja, pues el índice de la comisión de estos delitos va en aumento. Lo anterior, permite concluir que la labor de creación de las leyes debe ser producto de un ejercicio conjunto, al que deben concurrir también no solo los operadores jurídicos, sino la academia, a partir de sus trabajos investigativos.

\section{Política criminal del Estado colombiano}

En este factor de la investigación se analizarán dos aspectos: (i) La duración de un proceso penal tramitado ante los juzgados penales municipales; y (ii) La política criminal adelantada por el Estado.

\section{Duración de procesos penales}

Al revisar las etapas procesales dentro de los procesos estudiados, se observa que se cumplen con los elementos esenciales que rodean el tipo de audiencia, por lo que se podría afirmar que el Sistema Penal actual es efectivo, pues garantiza a las partes e intervinientes los derechos que se encuentran en juego en cada una de las etapas procesales; sin embargo, otra es la cuestión al hablar del término en el que se lleva a cabo cada una de las etapas procesales.

De los datos obtenidos de los procesos penales que se tramitan en el C.J., se logró determinar que a medida que transcurría la implementación del SPOA en Bucaramanga, este Sistema judicial penal se fortalecía en el cumplimiento de los parámetros previstos en la norma para cada una de las etapas procesales.

En cuanto al parámetro de duración de los procesos, se observa en la gráfica que los procesos que iniciaban en el año 2006 se demoraban un promedio de 5 años para que se formulara imputación y otros casos llegaban a juicio oral en un promedio de 5,5 años, mientras que los procesos iniciados en el año 2010 se formulaba imputación en un término de 1,26 a 3 años, y algunos casos llegaban a juicio oral en un promedio de 2,9 años a 3 años, es decir, los procesos terminaron para el 2010 en un promedio de 2,5 años en comparación con la duración de los procesos que iniciaron en el año 2006. Así mismo, es necesario resaltar que desde los años 2006 al 2009, los procesos presentaron una duración de 4,6 años. 
Figura. 4. Linea temporal de los procesos del C.J. de la Universidad Santo Tomás Seccional Bucaramanga

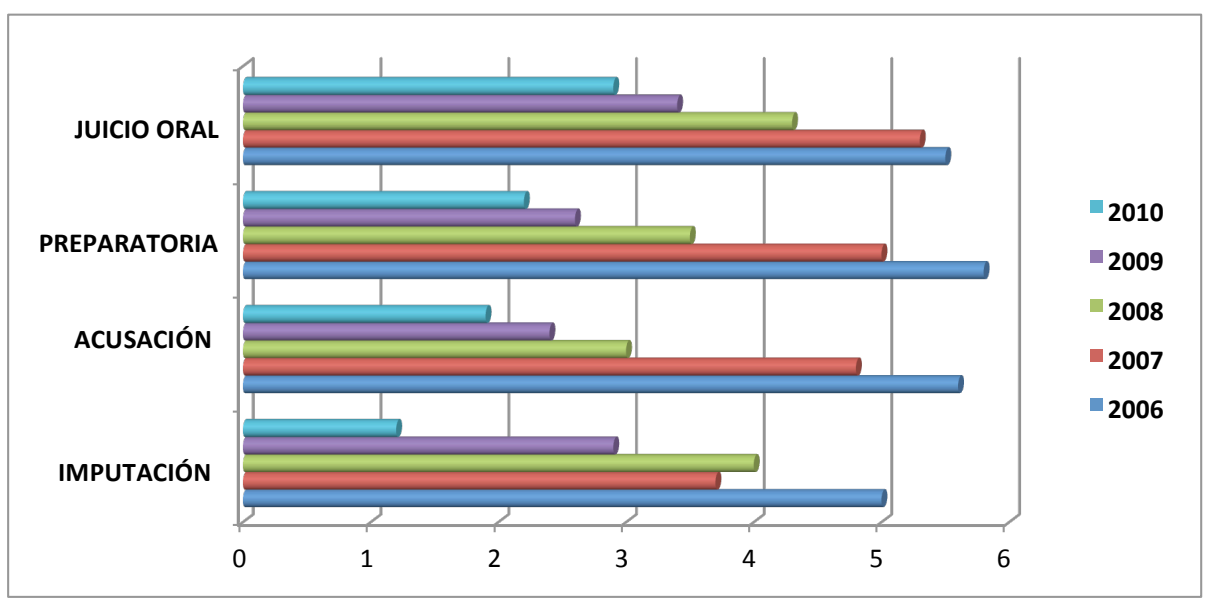

Fuente: Elaboración propia.

De acuerdo con la figura 4, se concluye que existe un avance en la consecución del principio de celeridad por parte del Sistema Penal Oral Acusatorio, en lo ateniente al cumplimiento de términos para adelantar las etapas procesales, ello si se tiene en cuenta que el Código de Procedimiento Penal (Ley 906 de 2004) contempla un promedio de duración de un proceso de 2,7 a 3,7 años ${ }^{24}$.

De igual manera, se podría afirmar en esta investigación que el SPOA es eficiente si únicamente se tuvieran en cuenta los resultados arrojados para los procesos iniciados en el año 2010, es decir, el Sistema Penal se ha venido fortaleciendo a medida que transcurre la implementación de este en Bucaramanga.

El retardo que presentaba la administración de justicia en la tramitación de los procesos de naturaleza querellable para los años 2006 al 2009 incidió de manera negativa en la concepción del Sistema por parte del ciudadano, en otras palabras, decae la imagen del Sistema judicial penal como escenario ágil para dirimir $\operatorname{conflictos}^{25}$, teniendo en cuenta que un proceso de este tipo se estaba demorando casi el doble del término señalado por la ley para finalizar el proceso.

Una de las posibles causas de la demora en la solución de estos procesos se originó en las modificaciones legislativas de que fueron objeto los delitos contra

24 Se debe tener en cuenta que para los términos de imputación y acusación aumentan siempre y cuando se encuentre una situación de concurso de delitos o la presencia de tres o más procesados.

25 En este aspecto no se afirma que la responsabilidad de la demora en el trámite de los procesos recae únicamente en el Sistema Judicial, por cuanto, en algunos casos se debe a situaciones provenientes de las partes (Fiscalía, Defensa o procesado) o la víctima o su representante. 
el patrimonio económico, integridad personal y familia. A algunos delitos como la inasistencia alimentaria y la violencia intrafamiliar se les cambió su naturaleza de querellables a oficiosos ${ }^{26}$, en este sentido, las partes no pueden acudir a otros mecanismos para la solución del conflicto, toda vez que el trámite procesal debe surtirse totalmente en instancias judiciales. Las otras reformas legislativas de las que han sido objeto los tipos penales mencionados anteriormente, han girado en torno al aumento de la pena.

La manifestación del Estado a través de las modificaciones legislativas contraría el principio penal de mínima intervención estatal en el marco del derecho penal, así mismo, estas modificaciones no responden a una política criminal de carácter reflexivo, sino de carácter reactivo; es decir, el aparato estatal reacciona al momento de la aparición de fenómenos sociales de gran relevancia, y como resultado de ello se obtiene una regulación o reforma normativa, desvaneciendo de tal manera el principio que establece que el derecho penal es la última ratio a la que se debe acudir para dar solución a los conflictos.

La verdadera eficacia de una política criminal radica en la participación activa de todos los actores que se encuentran involucrados en la sociedad (ONG, fundaciones, universidades, empresas, entre otras), en la creación de una política que cuente con un enfoque preventivo. La Universidad Santo Tomás, a través del C.J. de la Facultad de Derecho, apoya la labor de descongestión judicial y de prevención de los conflictos mediante la ejecución del programa de proyección social que permite capacitar a la población vulnerable en temas de mediación y mecanismos de participación, con el fin de procurar una solución pacífica a los conflictos sociales y así evitar acudir a los estrados judiciales.

\section{POLÍTICA CRIMINAL DEL ESTADO COLOMBIANO}

La noción de "política criminal" ha sido definida por la Corte Constitucional ${ }^{27}$ (2010) como:

El conjunto de respuestas que un Estado estima necesario adoptar para hacerle frente a conductas consideradas reprochables o causantes de perjuicio social, con el fin de garantizar la protección de los intereses esenciales del Estado y de los derechos de los residentes en el territorio bajo su jurisdicción.

La Comisión asesora de política criminal (2012) expresa que la política criminal en Colombia debe estructurarse desde un aspecto normativo, a partir de los principios y derechos constitucionales establecidos en la Carta Política y en los instrumentos

26 Para este tipo de delitos el Código Procesal Penal contemplaba mecanismos de solución del conflicto: tales como la conciliación como requisito de procesabilidad, la preclusión y el principio de oportunidad permitiendo al procesado bajo la orientación del defensor penal, evitar llegar hasta el juicio oral y acceder a los otros medios; sin embargo, actualmente presentan la condición de delitos de carácter oficioso.

27 Corte Constitucional. Sentencia C-936 de 2010. 
internacionales que protegen los derechos humanos; y desde un aspecto fáctico, a partir del estudio y análisis de la realidad de la sociedad.

Al momento de crear una política criminal, el Gobierno debe tener en cuenta los siguientes factores:

(i) Definición de sus elementos constitutivos y las relaciones entre ellos, (ii) articulación inteligible de sus componentes, y (iii) programación de la forma, los medios y el ritmo al cual será desarrollada dicha política; en ese orden de ideas, las decisiones constitutivas del diseño de una política pública pueden ser plasmadas, o bien en documentos políticos, o bien en instrumentos jurídicos -esto es-, normas, sean éstas de rango constitucional, legal o reglamentario (Corte Constitucional, 2010).

Posterior a la adecuación de los factores que constituyen la política, se acude a las medidas normativas penales para ejecutar esta política, la cual debe: (i) Definir los bienes jurídicos que se buscan proteger-tipificación de conductas; (ii) establecer las penas; (iii) el procedimiento para proteger los bienes jurídico protegidos; (iv) establecer criterios para una eficaz administración de justicia; (v) instituir mecanismos de protección para las partes e intervinientes en el proceso penal; (vi) regular la detención preventiva; (viii) señalar los términos de prescripción de la acción penal (Comisión Asesora de Política Criminal, 2012).

Es así que, la relación entre derecho penal y política criminal se basa en que esta última utiliza al derecho penal como instrumento para su ejecución; y el derecho penal implementa los medios para combatir el crimen y alcanzar los logros establecidos en la política criminal. Un ejemplo de lo anterior, es el adecuado diseño y adopción de modelo de política criminal establecido en el Acto Legislativo No. 3 de 2002, por medio del cual se implementó un "nuevo sistema" de investigación, acusación y juzgamiento en materia penal.

De lo expuesto anteriormente, se arrojan dos grandes conclusiones: la primera de ellas se relaciona directamente con la existencia de una política criminal de Estado orientada hacia la creación del delito, desde la perspectiva de persecución del crimen; en este sentido, se observa que no hay una determinación clara del Estado, en cuanto a especificad del delito; sin embargo, se requiere un estudio en torno al deber ser del sistema penal, con el fin de prevenir en lo posible la intervención judicial.

La segunda conclusión se encuentra directamente relacionada con las causas que motivan la eficiencia del Sistema Penal, que permite que la academia pueda aportar consideraciones desde el punto de vista cualitativo y cuantitativo que a su vez podrían motivar una reforma estructural al SPOA, en cuanto a creación o supresión de cargos judiciales, refuerzo e identificación de falencias dentro del sistema, y cuantificación de la percepción de justicia en materia de operatividad e impunidad.

En este sentido, la investigación de la que hoy se presentan resultados propone la creación del Observatorio del Sistema Penal Oral Acusatorio de la Universidad Santo Tomás, con el fin de hacer seguimiento al Sistema. A través de este Observatorio, se buscará evaluar el grado de efectividad y garantismo de los derechos inmersos en el 
proceso penal por medio de investigaciones que permitan la creación de parámetros para dar cumplimiento de los fines del Sistema Penal Oral Acusatorio. Igualmente tendrá como misión fomentar la investigación en los temas de garantismo judicial en los procesos penales y la promoción de la protección de los derechos fundamentales, con el fin de contribuir al cumplimiento de los fines y principios del Sistema Penal Oral Acusatorio y propender a la obtención de la justicia dentro de un Estado social de derecho.

Sin necesidad de hacer una cuantificación exhaustiva de la evolución legislativa en materia penal, la investigación puede concluir que la política criminal del Estado en Colombia es ineficiente.

Si se observa desde la entrada en vigencia del SPOA se han efectuado múltiples reformas en materia de conductas delictivas; sin embargo, en lo que toca los tipos penales objeto de la investigación, se observa una tendencia en materia de política criminal, a la creación de más disposiciones prohibitivas o al aumento en las existentes en materia de punibilidad. No obstante, las cifras obtenidas permiten concluir ${ }^{28}$ que contrario a la existencia de un derecho penal mínimo caracterizado por la intervención restrictiva del Estado en materia de conflictos sociales de naturaleza penal, las disposiciones legislativas están orientadas hacia una ampliación de estos límites punitivos.

\section{DESJUDICIALIZACIÓN DEL CONFLICTO Y CREACIÓN DE MECANISMOS ALTERNOS}

Respecto al tema de los Mecanismos alternativos de solución de conflictos de naturaleza penal, se puede afirmar que contrario a una política criminal de Estado orientada hacia la eliminación de requisitos, las modificaciones legislativas como las incorporadas por la Ley 1542 de $2012^{29}$ han limitado el acceso a estos mecanismos, un ejemplo de estos es la solicitud de terminación del proceso elevada ante el Fiscal de conocimiento por acuerdo entre el investigado y la víctima, en los procesos penales adelantados por la violencia intrafamiliar y la inasistencia alimentaria.

La ambivalencia legislativa ha motivado, entre otras cosas, que en ocho años de funcionamiento del Sistema Penal Oral Acusatorio, el delito de violencia intrafamiliar haya cambiado su naturaleza de querellable y no querellable por lo menos en dos oportunidades (Ley 1142 de 2007, Ley 882 de 2004, Ley 1542 de 2012), y la inasistencia alimentaria haya perdido tal condición de querellable en

28 En el caso de los delitos contra la familia desde el año 2006 al 2010 se aumentaron un 91\%, en los delitos contra el patrimonio económico, existió un aumento del 58\% y en el caso de los delitos contra la vida e integridad personal en un 64\%. Cifras tomadas de los 278 procesos analizados durante la investigación.

29 Por la cual se reforma el artículo 74 de la Ley 906 de 2004, eliminando el carácter querellable y desistibles de los delitos de violencia intrafamiliar e inasistencia alimentaria. 
razón de la última reforma citada, situaciones que si bien condicionan el actuar de los estudiantes ${ }^{30}$ en el campo práctico al imperio de la ley, no impide la utilización de criterios adicionales que permita la terminación del proceso sin necesidad de acudir hasta el juicio oral en los casos donde exista acuerdo libre y voluntario de las partes ${ }^{31}$.

En materia de terminación anticipada del proceso podría el C.J., por intermedio de su Centro de Conciliación, convocar a las partes para que lleguen a un acuerdo en los procesos penales por estos delitos, pero como quiera que las normas citadas, aun cuando contradictorias permiten interpretaciones orientadas hacia su desarrollo, el Consultorio puede ofrecer estos mecanismos alternativos con la finalidad de cumplir con los siguientes postulados procesales:

1. Solicitudes de preclusión de conformidad con el artículo 37 del Código de Procedimiento Penal inciso final, que establece que en delitos de competencia de los jueces municipales "La investigación de oficio no impide aplicar, cuando la decisión se considere necesaria, los efectos propios de la querella para beneficio y reparación integral de la víctima del injusto". Criterio que desarrollado desde la perspectiva de la mínima intervención y la conveniencia de la actuación penal en delitos de naturaleza querellable, sustenta perfectamente el curso del proceso, fundamentado en todo caso en la actuación previa del Centro de Conciliación y la conciliación como mecanismo alternativo.

2. La aplicación del principio de oportunidad como alternativa de finalización del proceso que, si bien no puede ser solicitado directamente por el estudiante de C.J., motiva eventualmente acercamientos académicos entre los alumnos con los medios cognoscitivos obtenidos durante la investigación penal, lo que permite inferir una mínima intervención determinados por factores, como los establecidos en el numeral 7 del artículo 324 del Código de Procedimiento Penal, el cual expresa "Cuando proceda la suspensión del procedimiento a prueba en el marco de la justicia restaurativa y como consecuencia de este se cumpla con las condiciones impuestas".

\section{CONCLUSIONES}

La teoría de Ferrajoli ha influenciado el Sistema Penal Oral Acusatorio colombiano, ello se observa en la labor del juez en torno a la protección de las garantías constitucionales dentro del procedimiento, por cuanto limita el ejercicio arbitrario del Estado para la prevención y represión en las conductas punibles, así como del castigo al procesado.

30 Estas reformas limitan el acceso, actuación e intervención de los defensores públicos en la terminación concertada con el agente fiscal de procesos penales adelantados por comportamientos como la violencia intrafamiliar y la inasistencia alimentaria.

31 En algunos juzgados se permite que el procesado llegue a un acuerdo con la víctima con la finalidad de dar por terminado el proceso mediante preclusión. 
A través de sus actuaciones los jueces han logrado evidenciar el cumplimiento y el respeto a los principios que rigen el Sistema Penal Oral Acusatorio, que son ejes esenciales en un Estado social de derecho; no obstante, después de haber transcurrido aproximadamente ocho años desde la implementación del Sistema Penal Oral Acusatorio en la ciudad de Bucaramanga, se observa que aún persisten falencias para un adecuado funcionamiento de este sistema.

Una de las primeras razones tiene que ver con las soluciones legislativas que no son consecuentes con el deber ser de la norma penal, pues el aumento en las penas y en el número de delitos que tipifican conductas cada vez más específicas, es directamente proporcional al aumento en las conductas criminales, especialmente en los delitos contra la familia, patrimonio económico y vida e integridad personal.

De esta situación, se observa el papel protagónico de las universidades como espacios de revisión, a través de investigaciones que contribuyan al fortalecimiento de las instituciones jurídicas. En este sentido, la Universidad Santo Tomás, con el fin de contribuir al cumplimiento de los objetivos del SPOA, se ha propuesto la creación del Observatorio del Sistema Penal Oral Acusatorio, con el fin de establecer parámetros de medición que permitirán seguir evaluando el Sistema Penal Oral Acusatorio, en los procesos que manejan los estudiantes adscritos a los C.J. de Bucaramanga, con la finalidad de fortalecer la actividad desempeñada por ellos, y contribuir con el cumplimiento de los fines del Sistema Penal Oral Acusatorio.

\section{REFERENCIAS}

Ambos, K. (2008). El principio acusatorio y el proceso acusatorio: un intento de comprender su significado desde la perspectiva histórica. Proceso Penal y sistemas acusatorios. Lorena Bachmaier (Coord.). Madrid: Winter, Marcial Ponds.

Baratta, A. (2004). Criminología crítica y crítica del derecho penal: introducción a la sociología jurídico penal. Argentina: Editorial Siglo XXI Editores S. A.

Barreto, L. y Rivera, S. (2009). Una mirada a la impunidad en el marco del Sistema Penal Oral Acusatorio en Colombia. Bogotá: Ministerio de Interior y de Justicia.

Código de Procedimiento Penal (2004). Ley 906 de 2004. Tomado de http://www. secretariasenado.gov.co/senado/basedoc/ley_0906_2004.html\#37

Corte Constitucional (2002). Sentencia C-806. M. P. Clara Inés Vargas Hernández.

Corte Constitucional (2010). Sentencia C-936. M. P. Luis Ernesto Vargas Silva.

Comisión Asesora de Política Criminal (2012). Informe final. Diagnóstico y propuesta de lineamientos de política criminal para el Estado colombiano. Recuperado de https://www.minjusticia.gov.co/Portals/0/INFO\%20POLI\%20CRIMINAL_ FINAL23NOV.pdf

Real Academia Española (2002). Diccionario de la Lengua Española (23. ${ }^{\mathrm{a}}$ ed.). Recuperado de http://www.rae.es/ 
Espino-Duque, G. (2010). Criminalidad en cifras: delitos en Colombia 2009. Recuperado de https:// https://www.policia.gov.co/imagenes_ponal/dijin/ revista_criminalidad/vol52_1/01Criminalidad.pdf.

Ferrajoli, L. (2004). Epistemología jurídica y garantismo. México: Biblioteca de Ética, Filosofía del Derecho y Política.

Observatorio del Delito de la Policía Nacional (2012). Investigación criminológica. Recuperado de http:// https://www.policia.gov.co/imagenes_ponal/dijin/ observatorio/src/005.pdf 